\title{
Uma experiência
de trabalho
no meio rural"
}

A

nossa intenção neste artigo é apresentar, em linhas gerais, uma experiência de trabalho, assim como as concepções que a orientam, para o debate. Por isso, esperamos receber críticas e sugestões que certamente contribuirão para enriquecer nosso trabalho e, com isto, nossa aprendizagem.

Em outubro de 1982 teve início o Projeto de Educação Integrada em Áreas Rurais, financiado através de convênio entre o CNPq, MEC (COAGRI), Ministério da Agricultura, Ministério do Trabalho e Universidade Federal da Paraíba. Esse Projeto, que atualmente conta com recursos provenientes de convênios INEP/UFPB e SEC-PB/UFPB, vem sendo desenvolvido por uma equipe interdisciplinar, formada atualmente por dois professores do Departamento de Psicologia, duas professoras do Departamento de Ciências Sociais, cinco psicólogas, uma pedagoga e duas estudantes de psicologia.

\section{Onde e Com Quem Trabalhamos}

O Projeto vem se realizando na comunidade rural denominada Jaque, situada no município de Cruz do Espírito Santo, a 45 quilômetros da capital do Estado da Paraíba. A região, de onde faz parte esse município, conhecida como Região da Várzea, é tradicionalmente vinculada à monocultura da cana-de-açúcar, matériaprima para usinas de açúcar e enge- nhos de aguardente ali existentes, com áreas cada vez mais reduzidas de lavoura de subsistência.

Jaque faz parte de uma área de terra de cerca de 330 hectares, anteriormente pertencentes ao Ministério da Agricultura, sendo que lá residem atualmente cerca de 135 famílias que vinham ocupando e explorando parcelas de terra das quais só tinham o uso, sem título de propriedade. A grande maioria desses moradores nasceram mesmo em Jaque, havendo casos de familias que moram e trabalhavam na terra há três gerações. Em 1984 , depois de uma longa luta, conseguiram os títulos de propriedade das terras ocupadas, que deverão ser pagas durante dez anos.

Essa área de terra apresenta quatro tipos de solo: tabuleiro, encosta, várzea e paul. Cada um desses tipos de solo, por suas características espeć́ficas, é utilizado para o plantio de culturas diferenciadas, e em épocas distintas do ano. A diversidade de tipos de solo condicionou a forma de

* Relato parcial de atividades desenvolvidas no Projeto de Educação Integrada em Áreas Rurais, $\mathrm{PB}$.

Equipe de trabalho: Bernadete de Oliveira $\mathrm{Nu}$ nes, Dirceu P. Malheiro, Eliana M. Moreira, Genaro Ieno Neto, Marinalva de Souza Conserva, Maria de Fátima P. de Souza, Maria José Mariano, Maria Milaneide de Souza, Mary Yale R. Neves, Síria Silva, Tereza C. da Nóbrega Queiróz, Thelma Maria G. Veloso ocupação da terra, bem como as formas de organização da produção.

A produção predominante é de horti-fruti-granjeiros, sendo que a unidade básica de produção está centrada na família, visando preponderantemente o consumo familiar, sendo o excedente comercializado no mercado, tendo por fim a obtenção de uma pequena renda monetária que permita a obtenção de bens não produzidos localmente.

Do ponto de vista da sobrevivência e reprodução da força de trabalho familiar, encontramos em Jaque uma diversidade e articulação de formas produtivas e relações de trabalho as quais, sinteticamente, poderiam ser agrupadas em:

famílias que garantem a sua subsistência exclusivamente a partir da produção em suas parcelas de terra;

famílias situadas em terras que além de serem improdutivas em determinados períodos do ano, têm uma dimensão reduzida $(0,5$ a dois hectares), insuficiente para garantir a subsistência da familia. Essas familias, embora trabalhem em suas parcelas de terra, se ocupam também alguns dias da semana como diaristas nas terras de outros pequenos proprietários, melhor situados financeiramente;

famílias que articulam o trabalho familiar e trabalho assalariado em usinas e engenhos da região;

famílias que moram em casas cedidas por outros moradores, em 


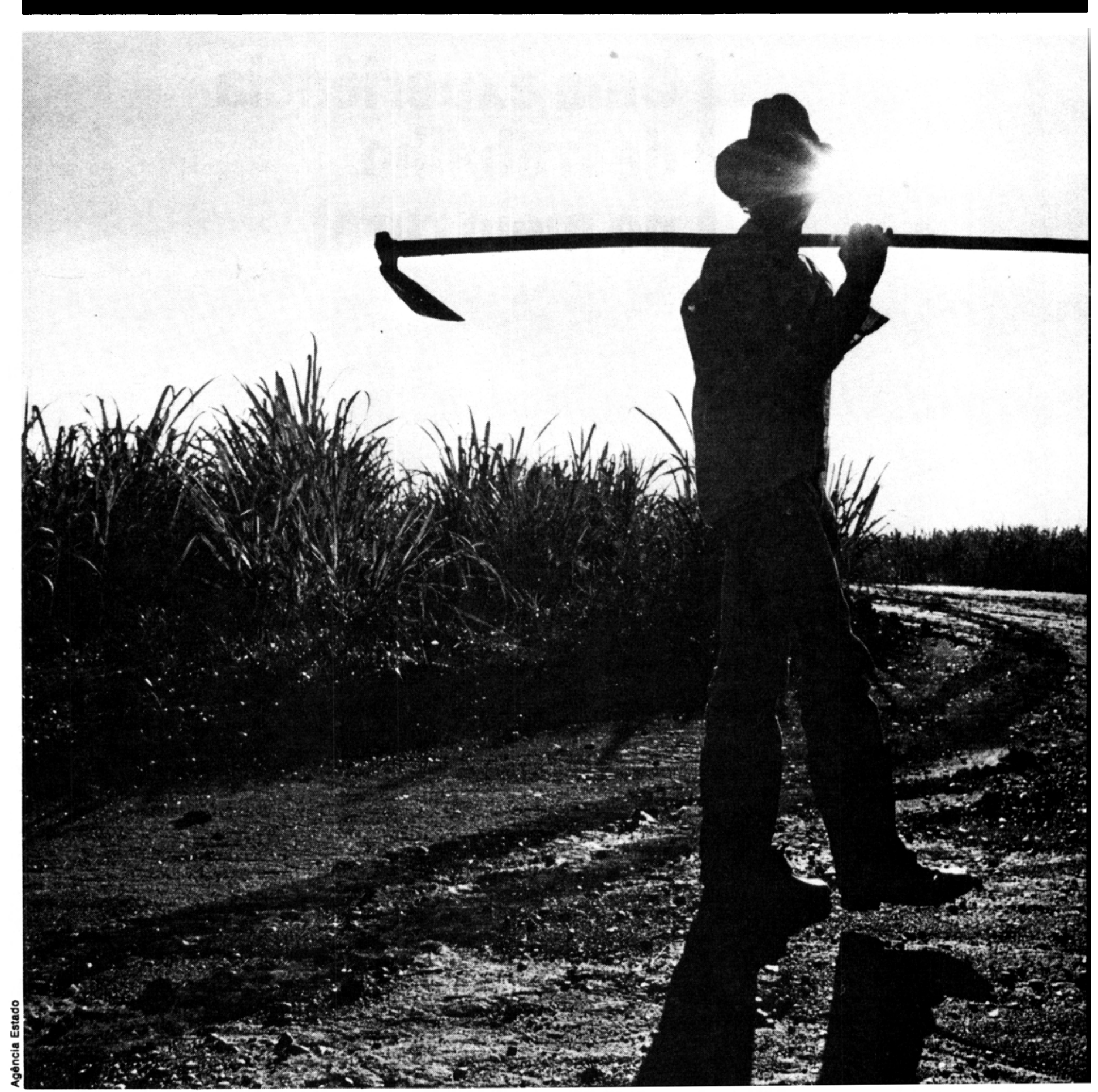

troca de trabalho nas terras destes últimos, sendo a produção obtida dividida entre ambos (membros destas familias trabalham também como assalariados nas usinas);

famílias que utilizam suas pequenas parcelas de terra como local de moradia, assegurando a subsistência através do trabalho assalariado no plantio e corte da cana-de-açucar nas terras das usinas e engenhos;

famílias que complementam suas rendas com os mais variados tipos de atividades não-agrícolas: bodegueiro, barbeiro, professor, cambista, tratorista, mecânico, etc.

\section{$\mathrm{O}$ que queremos}

Nossa prática inclui uma avaliação permanente da dinâmica do desenvolvimento da comunidade, o que tem permitido retificar vários aspectos do nosso trabalho. Por isso a formulação dos nossos objetivos tem sido modificada, e atualmente anunciamos o nosso objetivo básico como:
"Contribuir para que os agricultores de Jaque, a partir de sua visão de mundo, elaborada em consonância com suas condições concretas de existência, possam recriar espaços sociais onde repensem seus conhecimentos, na perspectiva de construção de um saber que possibilite a geração, de formas organizativas da população".

Portanto, o enunciado de nosso objetivo delimita precisamente nosso objeto de trabalho: "o processo de elaboração de conhecimento pelos 


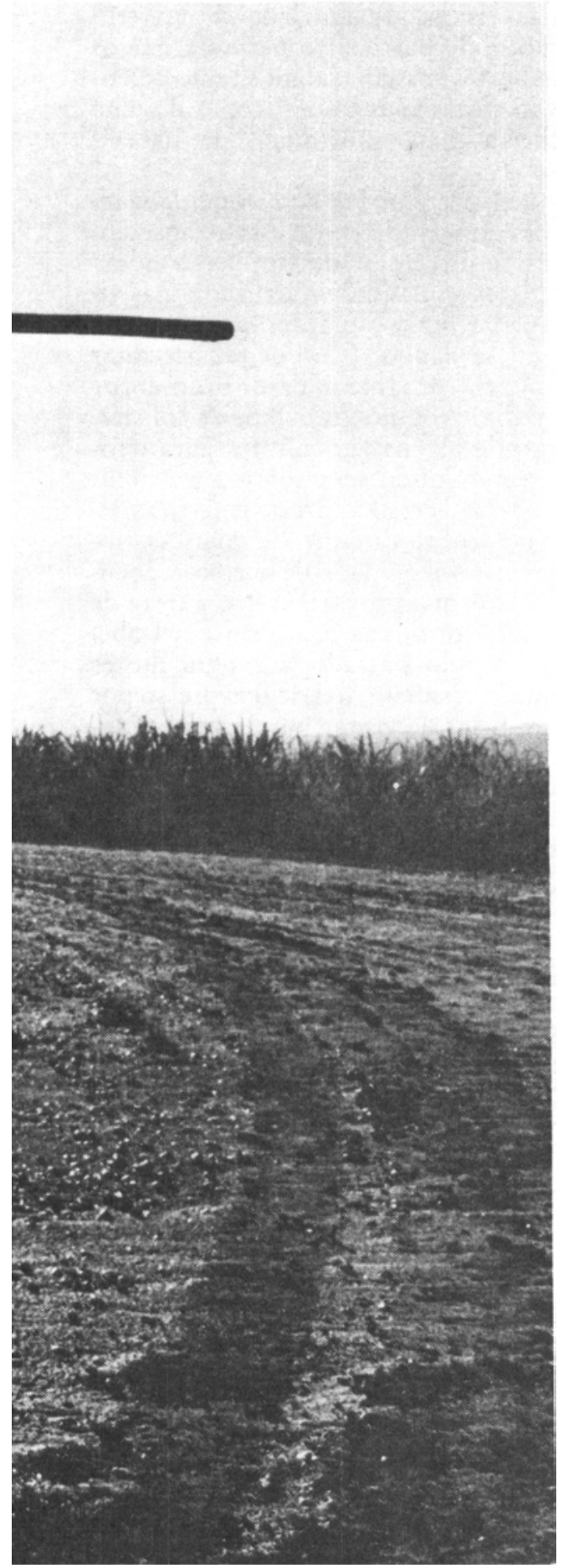

agricultores de Jaque". Mas não só: ele define também uma direção para o trabalho. Não é um conhecimento qualquer que nos interessa, enquanto nosso objeto de trabalho, mas um conhecimento operativo sobre suas condições concretas de vida, na perspectiva de ir transformando-as na direção de formas de convivência que estejam mais de acordo com seus interesses.

Além deste, o trabalho tem outros objetivos complementares, entre os quais detacamos os seguintes: "Articular a experiência realizada com as práticas de ensino e pesquisa desenvolvidas pelos professores e alunos dela participantes, visando contribuir para a formação de profissionais para este tipo de trabalho, sistematizar o desenvolvimento da experiência através de procedimentos que permitam a construção de um conhecimento compativel com os objetivos do trabalho e pertinente às áreas profissionais nela envolvidas".

\section{Como Fazemos}

A formulação do objetivo principal de nosso trabalho define uma opção por uma estratégia que dá prioridade à participação dos membros da comunidade de Jaque em todos os níveis de decisão. Opta por uma perspectiva de trabalho dentro do que tem sido chamado de "metodologia participativa".

Dizer que a estratégia geral se baseia em uma metodologia participativa significa, em outras palavras, que para nós a pergunta fundamental que fazemos no processo de avaliação permanente do trabalho é: "Qual a contribuição de nossa prática para ampliar o poder dos moradores de Jaque na construção de um saber que reforce as formas organizativas de defesa de seus interesses?"

Assim se tem procurado levar a uma participação efetiva dos moradores nas atividades desenvolvidas pelo trabalho.

Por isso, ao iniciarmos nossos contatos com os moradores de Jaque, optamos por não definirmos, a priori, que problemas seriam enfocados, mas sim nossa proposta era a de, através desses contatos irmos descobrindo, com eles, quais os problemas mais urgentes e que eles considerassem como os que deveriam ser enfrentados.

Paralelamente, tínhamos a preocupação de aproximar os conhecimentos teóricos que ensinamos/aprendemos no âmbito da Universidade, a uma realidade concreta, que apresentava problemas a serem superados.

Essa proposta de atuação era explicitada nos contatos com os moradores, nas visitas às suas casas e roçados.

Essas visitas se constituem na presença de, na maioria das vezes, duas pessoas de nossa Equipe nas residências ou nos locais de trabalho, onde conversamos informalmente com os agricultores individualmente e às vezes com suas famílias. Os conteúdos dessas visitas são os mais variados possíveis, dependendo do rumo da conversa, a qual se inicia por um assunto proposto por nós (dependendo do contexto onde ou em que situações a conversa está se dando, ou de planejamento anterior feito pela Equipe, é introduzido um determinado assunto nessas conversas), ou pelos agricultores.

No entanto, certos assuntos foram tratados com maior freqüência: a história pessoal, da família e de Jaque, ao mesmo tempo que era verbalizado o descontentamento e muitas vezes a revolta com o INCRA, que naquela época queria impor aos moradores de Jaqué uma forma de loteamento da terra que traria prejuízos sérios às famílias lá residentes, uma vez que desrespeitaria a forma com que historicamente se deu a ocupação dessa terra.

Após três meses de visitas semanais aos moradores, um deles fez a proposta de se realizar uma reunião entre eles e nós para se conversar sobre a atuação do INCRA. Frente a essa proposta, nós respondemos que se eles quisessem essa reunião era só marcar o dia, a hora e o local que nós iríamos. Transcorreram dois meses entre essa primeira proposta de reunião e a sua efetivação, período em que continuamos com as visitas informais às casas e aos locais de trabalho.

Essa primeira reunião contou com uma participação ativa de mais de duzentas pessoas entre homens, mulheres e crianças. A partir daí, os próprios moradores propuseram uma reunião por semana e o assunto prioritário passou a ser o problema com o INCRA. Depois de um ano de luta os agricultores conseguiram que o INCRA aceitasse fazer o loteamento conforme a proposta que tinham elaborado.

Esse periodo foi muito rico para o desenvolvimento do trabalho, uma vez que a comunidade conseguiu resolver, em parte, um de seus principais problemas - a segurança de ter terra para trabalhar nas condições mais ou menos inalteradas a que ela já estava acostumada a ter, e nos levou à compreensão mais aprofundada da dinâmica da vida da comunidade, ao mesmo tempo que possibilitou a reflexão sobre novas perspectivas de trabalho.

Pensando e repensando a prática Apresentamos, a seguir, algumas 
das discussões que temos feito sobre o nosso trabalho:

1 - Devido às diferentes formas de inserção de seus membros no processo produtivo, existem na comunidade interesses distintos em relação ao uso da terra. Este fato fez com que ter alcançado um objetivo concreto não significou necessariamente que foram dados passos na direção da construção de um saber que tenha um significado comum a toda a comunidade.

Além disso, na condição de posseiros e enfrentando um inimigo comum (o INCRA), se ouviam frases como: "a dor de um é a dor de todos". Hoje, como pequenos proprietários de terra, percebe-se uma modificação na relação com ela e ao mesmo tempo entre os próprios moradores, no sentido de uma crescente individualização, como a construção de cercas nos seus lotes, por parte de alguns desses moradores.

Com a continuidade das visitas, os moradores passaram a expressar interesses mais definidos conforme suas diferentes inserções na produção, ou seja: os assalariados têm expressado interesse em discutir aspectos relativos a seus direitos trabalhistas, enquanto trabalhadores na canade-açúcar; os pequenos produtores, que vivem exclusivamente do trabalho em suas áreas de terra, começam a nos chamar para discutir a possibilidade de terem acesso a uma área de terra vizinha, pertencente à EMATER, que está abandonada, além da necessidade de eletrificação da área. Dessa forma, novas possibilidades para o desenvolvimento do trabalho estão sendo colocadas pelos próprios moradores de Jaque.

Esses fatos nos levam a questionar a nossa concepção a cerca da comunidade como um grupo social homogêneo.

2-Acreditamos que as reuniões da comunidade seriam o espaço privilegiado para uma ação coletiva. No início do trabalho pensávamos ser imprescindível a existência de reuniões da comunidade - das quais participaríamos, por serem um espaço para nossa atuação - pois consideramos que é na ação coletiva que os agricultores podem superar, com o saber que possuem, o que existe de reprodução das relações de dominação vigentes na sociedade e assim resgatar o que lhes é próprio.

No entanto, com o desenvolvimento da experiência, fomos revendo essa compreensão, por dois motivos: a - os agricultores têm suas formas próprias de organização, desenvolvidas historicamente, com estratégias de convivência entre eles, vinculadas às suas condições concretas de vida. Assim têm seus próprios espaços de reunião: a bodega no final de semana, o jogo de futebol, a casa de farinha, o terreiro da casa na boca da noite, o lugar do banho e da lavagem de roupa na beira do rio etc. Estes são seus próprios espaços, entre outros, onde eles se encontram e conversam sobre assuntos relativos às suas próprias vidas. Mas não só conversam, como tomam decisões. Por isso, não são as nossas reuniões (nós e eles) o único nem, necessariamente, o melhor lugar onde os agricultores podem trabalhar as concepções que têm de suas vidas e do mundo, e a partir delas tomar decisões sobre o que fazer.

Isto não quer dizer que as nossas reuniốes não têm um papel determinado e, em alguns momentos, importante. Significa, apenas, que temos de estar atentos na avaliação do desenvolvimento do trabalho, à função dessas reuniões nesse processo, para podermos ter condições de perceber que em determinados períodos elas podem ser desnecessárias, ou estarem até sendo uma forma de impor aos agricultores uma maneira de trabalhar tipicamente nossa.

b - Mas deixando de existir as reuniōes da comunidade nosso papel não desaparece. Pois compreendemos que as visitas são também momentos de produção de conhecimento, para nós e para eles, uma vez que procuramos aprofundar o mais possível as discussões sobre os assuntos que nelas emergem. Temos observado que o conhecimento produzido dessa forma não fica perdido nas visitas, pois, muitas vezes, ele é retomado em outras conversas subseqüentes com o mesmo agricultor, ou conversas tidas com um deles são retomadas por outros, mostrando que os agricultores falam entre si sobre os assuntos tratados conosco nessas visitas.

Evidentemente o conhecimento que é produzido nas visitas não tem as mesmas características do que é produzido numa ação mais coletiva, do tipo reuniōes. Muitos dos assuntos tratados nas visitas eram retomados por nós ou pelos agricultores nas reuniões da comunidade estabelecendo assim, uma interrelação entre o que é, e como esses assuntos eram tratados nas visitas, de um lado, e nas reuniōes, de outro. Isto permitia que os assuntos fossem tratados tanto coletivamente nas reuniões, como de uma forma mais individualizada nas visitas.

Nas reuniōes da comunidade temos observado como essa relação entre a discussão de um tema numa situação mais individualizada (nas visitas) e uma situação mais coletiva está se dando. Isto nos faz acreditar que ela produzirá desdobramentos qualitativos no trabalho. A solicitação de alguns agricultores para retomarmos discussões sobre a possibilidade de acesso às áreas de terras vizinhas, sobre direitos trabalhistas, sobre a possibilidade de acesso a documentos que provariam que a terra de Jaque foi doada pela Princesa Isabel no século passado aos agricultores que lá residiam, o desejo expresso por um deles de visitar outras comunidades rurais onde ele tem conhecimento de que o "povo desses lugares está se unindo pra revolver seus problemas", são indicativos disso. Essas solicitações têm sido refletidas com eles no sentido de descobrir formas de viabilizá-las.

A experiência nos tem colocado a necessidade de aprofundarmos a questāo da relação entre o nível mais individual e o mais coletivo da produção do saber popular. Ou seja, talvez seja necessário desenvolvermos uma compreensão mais clara sobre a epistemologia do saber popular quanto à dimensão particular/geral, individual/ coletivo.

3 - Os agricultores de Jaque, como pertencentes às classes dominadas da sociedade, possuem suas estratégias de sobrevivência e resistência desenvolvidas historicamente. Esse saber, por ser dominado, não tem espaços para ser sistematizado por seus próprios autores e é por eles, sabiamente, mantido em silêncio. Porém, todo silêncio contém sempre algo de novo. Aqui, na nossa compreensão, está entre outros, o nosso papel: o espaço de participação que o nosso trabalho tem pretendido criar e vivenciar; tem procurado, em primeiro lugar respeitar, para poder captar, compreender e colocar em questão junto aos agricultores suas próprias estratégias. Dessa forma, eles poderão ir descobrindo a força do novo que o silêncio que lhes é imposto contém. Nesse processo temos aprendido muito e certamente temos muito mais ainda a aprender. No entanto, o nos- 
so saber também tem tido e deverá continuar tendo a sua importância e, por isso, deveremos estar sempre atentos para garantirmos, na prática do trabalho, uma articulação criativa entre o nosso saber de professores, alunos e profissionais de nivel universitário e o saber dos agricultores de Jaque, sempre em função de seus interesses.

Por exemplo: durante o período em que os agricultores estavam se confrontando com a intervenção do INCRA, eles próprios apresentaram propostas divergentes quanto à forma de enfrentar essa intervenção. Cada uma dessas estratégids foi discutida pelo próprios trabalhadores juntamente conosco, permitindo que eles explicitassem entre si as concepções subjacentes a cada uma dessas propostas, até conseguirem ter condições de decidir por qual delas optar. Nessa situação apresentávamos informações que julgávamos pertinentes nas discussões como: relatos de experiências semelhantes vividas por outros trabalhadores, sugestões de se convidar advogados, sindicalistas e outros trabalhadores que pudessem participar das reuniões da comunidade, sugestões de visitas de pessoas de Jaque a outras áreas onde agricultores também tiveram que enfrentar a intervenção do INCRA.

4 - O contato que temos tido com os moradores de Jaque nas reuniōes e principalmente nas visitas nos possibilitou observar que a quase totalidade do discurso dessas pessoas tem uma lógica que temos chamado de "lógica histórica": para quase todo assunto sobre o qual eles conversam conosco, ou entre eles, têm uma história ou um caso para contextualizar suas opiniões.

Os problemas vividos hoje pelos trabalhadores rurais de Jaque guardam estreita relação com a conjuntura atual (presente) histórica (passado), tanto a nível regional como nacional, assim como com a perspectiva de vida futura que esses trabalhadores têm elaborado. Assim passado, presente e futuro se articulam na determinação dos problemas vividos hoje pelos trabalhadores. Por isso, através da prática de noso trabalho junto aos agricultores, atuar no presente para transformar o futuro depende, entre outras coisas, de como se analisa o passado.

É baseado nessa compreensão que temos pretendido situar como elemento de análise dos problemas colocados pelos trabalhadores, a história de como cada um deles aparece e têm sido enfrentados por eles. As sim, os problemas devem ser trabalhados tanto nas reuniões como nas visitas, tendo como um dos aspectos como esse problema aparece na história dos trabalhadores de Jaque.

Essa análise histórica feita com os trabalhadores, deve produzir pelo menos quatro desdobramentos:

a - descobrir como a história do problema em Jaque (ou com uma determinada pessoa) se articula com a história em nível regional e geral da sociedade;

b - criar condições para alargar a compreensão da situação atual e das possibilidades de mudança em relação aos problemas analisados; c possibilitar a discussão de como o(s) trabalhador (es) considera(m) que a sociedade deveria estar organizada para que o problema em questão pudesse ser superado. Essa discussão poderá contribuir para que os trabalhadores possam ir formulando, por eles mesmos, o germe'de um modelo de sociedade segundo suas próprias percepções, na perspectiva deles irem criando uma direção para um futuro comum que lhes oriente a luta e a própria vida.

d - possibilitar que os trabalhadores percebam que eles têm um conhecimento (sobre sua história) que lhes é significativo, porque é uma ferramenta de ação sobre o presente na perspectiva de construir um futuro menos obscuro.

Novamente aqui a participação dos trabalhadores no resgate de sua história é fundamental, pois em História os fatos são analisados a partir da visão que as fontes que os relatam possuem. Para nós, não é a objetividade do que é relatado que importa, mas o que foi lembrado, o que é escolhido para ser recordado.

5 - Por fim, gostaríamos de assinalar alguns procedimentos e posturas que nos têm parecido importantes no desenvolvimento do trabalho, além dos já relatados:

a - a troca de experiência entre os agricultores de Jaque com outros trabalhadores com experiência afins, têm se mostrado com uma circunstância muito rica no sentido de abrir possibilidades de ação e de compreensão sobre os problemas que estão sendo enfrentados, pois isto se dá no quadro de referências dos próprios trabalhadores envolvidos na situação:

b - a utilização de filmes e dis- positivos sobre tomadas de interesse expresso pelos agricultores tem correspondido à sua necessidade de informações e de discussões. Além disso, dessa forma, se articula este tipo de necessidade que possuem com uma forma de lazer que, apesar de não lhes ser habitual, é bastante valorizada, principalmente os filmes e os diapositivos.

$\mathrm{c}$ - temos atuado no interior da equipe visando criar espaços onde reflexões coletivas tenham lugar no sentido de construir um saber sobre a prática desenvolvida;

d - a experiência tem possibilitado rever tanto os conteúdos como os procedimentos que os professores desenvolvem com seus alunos em sala de aula, nas disciplinas que lecionam;

e - a partir da experiência que vem sendo realizada, estão sendo elaboradas uma tese de doutorado e quatro de mestrado por membros da equipe de trabalho;

$f$ - a experiência de um trabalho interdisciplinar tem permitido discutir o papel de cada uma das categorias profissionais nela envolvidas (psicólogos, sociólogos e educadores) quanto ao tipo de contribuição que cada uma delas presta ao trabalho e em que medida a prática deste trabalho têm contribuído para repensarmos o conteúdo de cada uma - assim como tem colocado a necessidade da discussão da questão do conhecimento especializado versus a não compartimentalização do conhecimento. Nesse sentido o trabalho interdisciplinar tem-se mostrado extremamente útil quanto às possibilidades de compreensão da realidade que está sendo trabalhada, uma vez que nenhuma das áreas profissionais envolvidas daria conta dessa compreensão isoladamente. As questões que a prática do trabalho apresenta são analisadas coletivamente, pela equipe, sem uma preocupação de definir, a priori, a qual das áreas profissionais elas estariam mais afetas. Assim, os enfoques de cada ciência particular se colocam no processo de uma discussão onde o objetivo é compreender os fenômenos que ocorrem na prática do trabalho com a ajuda das várias ferramentas teóricas de que dispomos.

$\mathrm{g}$ - por tudo que foi relatado deve ter ficado claro que estamos interessados no processo de desenvolvimento da experiência vivida junto com os agricultores de Jaque. Não nos interessa somente um produto final acabado. 